九州大学学術情報リポジトリ

Kyushu University Institutional Repository

Preformed C1q-binding Donor-specific Anti-HLA Antibodies and Graft Function After Kidney Transplantation

岡部，安博

http://hdl. handle. net/2324/4110420

出版情報 : 九州大学，2020，博士（医学），論文博士

バージョン:

権利関係: (C)2018 Elsevier Inc. All rights reserved. 


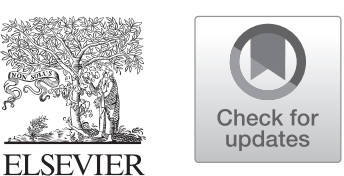

\title{
Preformed C1q-binding Donor-specific Anti-HLA Antibodies and Graft Function After Kidney Transplantation
}

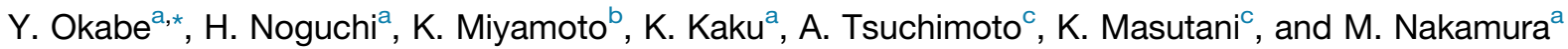 \\ ${ }^{a}$ Department of Surgery and Oncology, Graduate School of Medical Sciences, Kyushu University, Fukuoka, Japan; ${ }^{\mathrm{b} C e n t e r ~ f o r ~ C e l l u l a r ~}$ \\ and Molecular Medicine, Kyushu University, Fukuoka, Japan; and ${ }^{\mathrm{C}}$ Department of Medicine and Clinical Science, Graduate School of \\ Medical Sciences, Kyushu University, Fukuoka, Japan
}

\begin{abstract}
Background. De novo complement-binding donor-specific anti-human leukocyte antigen antibodies (DSAs) are reportedly associated with an increased risk of kidney graft failure, but there is little information on preformed complement-binding DSAs. This study investigated the correlation between preformed C1q-binding DSAs and medium-term outcomes in kidney transplantation (KT).

Methods. We retrospectively studied 44 pretransplant DSA-positive patients, including 36 patients who underwent KT between April 2010 and October 2016. There were 17 patients with C1q-binding DSAs and 27 patients without C1q-binding DSAs. Clinical variables were examined in the 2 groups.

Results. Patients with C1q-binding DSAs had significantly higher blood transfusion history $(53.0 \%$ vs $18.6 \% ; P=.0174)$, complement-dependent cytotoxicity crossmatch (CDC-XM)-positivity $(29.4 \%$ vs $0 \% ; P=.0012)$, and DSA median fluorescence intensity (MFI) $(10,974$ vs $2764 ; P=.0009)$. Among patients who were not excluded for $C D C$ $X M$-positivity and underwent KT, there was no significant difference in cumulative biopsy-proven acute rejection rate $(32.5 \%$ vs $33.5 \% ; P=.8354)$, cumulative graft survival, and 3-month and 12-month protocol biopsy results between patients with and without C1q-binding DSAs. Although patients with C1q-binding DSAs showed a higher incidence of delayed graft function $(54.6 \%$ vs $20.0 \% ; P=.0419)$, multivariate logistic regression showed that DSA MFI $(P=.0124)$, but not C1q-binding DSAs $(P=.2377)$, was an independent risk factor for delayed graft function.

Conclusions. In patients with CDC-XM-negativity, preformed C1q-binding DSAs were not associated with incidence of antibody-mediated rejection and medium-term graft survival after KT. C1q-binding DSAs were highly correlated with DSA MFI and $C D C-X M$-positivity.
\end{abstract}

$\mathbf{K}$ IDNEY transplantation (KT) for end-stage renal disease has been associated with substantial reductions in the risk of mortality and cardiovascular events, as well as clinically relevant improvements in quality of life [1]. At the same time, it has been recognized that sensitized renal transplant recipients with high levels of donor-specific antihuman leukocyte antigen antibodies (DSAs) commonly develop antibody-mediated rejection (AMR), which may cause acute graft loss or shorten allograft survival [2-4].

In modern solid organ transplantation, human leukocyte antigen (HLA) laboratories regularly perform crossmatches between donor cells and recipient serum before transplantation. The close association between complementdependent cytotoxicity crossmatch (CDC-XM)-positivity and early graft loss has been reviewed [5], and since the

*Address correspondence to Yasuhiro Okabe, Department of Surgery and Oncology, Graduate School of Medical Sciences Kyushu University, 3-1-1 Maidashi, Higashi-ku, Fukuoka 8128582, Japan. Tel: +81 92-642-5441; Fax: +81 92-642-5457. E-mail: y-okabe@surg1.med.kyushu-u.ac.jp

(c) 2018 Elsevier Inc. All rights reserved. 230 Park Avenue, New York, NY 10169 
introduction of the single antigen bead (SAB) assay, DSAs are being increasingly recognized as a major problem in KT. Many studies have indicated an increased risk of AMR and inferior outcomes when transplantation is performed in the presence of DSAs detected by the SAB assay, even with crossmatch-negativity [6-8]. However, not all DSAs have the same effect on allograft function [8-10]. One reason for this is that complement fixation capacity has been identified for potent cytotoxic anti-HLA antibodies, which can be associated with allograft rejection [11-13]. Of the 3 complement-dependent pathways, the classical pathway involves antibody $\mathrm{Clq}$ fixation. Antibodies binding to an antigen and the subsequent binding of $\mathrm{Clq}$ initiate activation of the complement cascade. While the conventional $\mathrm{SAB}$ assay was designed to detect both complement-binding and non-complement-binding antibodies, the $\mathrm{C} 1 \mathrm{q}$ assay, a modified SAB assay designed to detect anti-HLA antibodies capable of binding to C1q, was recently reported [14]. A commercial $\mathrm{Clq}$ kit is now available that can detect complement-binding anti-HLA antibodies using beads in the Luminex system or cells (Luminex, Austin, Tex, United States), and can also be used with cell-based flow cytometry. It has been shown that de novo C1q-binding DSAs are associated with an increased rate of AMR and an increased risk of graft loss [15-17]. However, there are few studies on the impact of preformed C1q-binding DSAs in KT $[18,19]$. In the present study, we investigated the correlation between pretransplant C1q-binding DSAs and the clinical outcomes of KT.

\section{MATERIALS AND METHODS Patients}

We reviewed 44 patients with pretransplant DSAs who underwent immunologic examination for KT at Kyushu University Hospital from April 2010 through December 2016. Of the 44 patients, 36 underwent KT between April 2010 and October 2016. The medical records and pathological reports of allograft biopsies were reviewed to obtain the baseline characteristics and clinical data. The study was approved by the Ethics Committee of Kyushu University and conducted according to the Declaration of Helsinki. CDC-XM, flow cytometry crossmatch (FCXM), DSAs, and C1q-binding DSAs were measured in same-day samples taken before desensitization.

\section{Complement-dependent Cytotoxicity Test}

Donor T-cells and B-cells were isolated using EasySep (StemCell Technologies, Vancouver, Canada). One microliter of donor cell suspension $\left(1.5-3 \times 10^{6}\right.$ cells $\left./ \mathrm{mL}\right)$ was incubated with $1 \mu \mathrm{L}$ of recipient serum for $60 \mathrm{~min}$ at $37^{\circ} \mathrm{C}$. Rabbit complement was added to the cells and incubated for $120 \mathrm{~min}$ at room temperature. The cells were stained with FluoroQuench AO/EB (One Lambda, Canoga Park, Calif, United States), and observed for cytotoxicity using a microscope (Eclipse Ts2-FL, Nikon, Tokyo, Japan). CDC$\mathrm{XM}$ results for $\mathrm{T}$-cells and $\mathrm{B}$-cells were considered positive when cell death exceeded that in negative control wells by $11 \%$.

\section{Flow Cytometry Crossmatch Test}

For the assay, $50 \mu \mathrm{L}$ of donor lymphocytes $\left(5 \times 10^{6} / \mathrm{mL}\right)$ was added to $50 \mu \mathrm{L}$ of patient serum and incubated for $30 \mathrm{~min}$ at room temperature. After washing, fluorescein isothiocyanate-labeled antihuman IgG and phycoerythrin-labeled CD19 (Becton Dickinson Biosciences, Franklin Lakes, NJ, United States) or PerCP-Cy5.5 CD3 (Becton Dickinson Biosciences) were added and incubated for $30 \mathrm{~min}$ at $4^{\circ} \mathrm{C}$. After washing, the cells were analyzed in a flow cytometer (FACSCanto II; Becton Dickinson Biosciences). A positive FCXM was defined as displacement of the mean channel fluorescence by more than 10 channels relative to the negative control and donor autologous control. Positive cases were further confirmed by their relative median fluorescence. For this, positive cases were defined as an FCXM ratio (sample median data/control median data) $>1.5$ for T-cells and $>2.0$ for B-cells.

\section{Detection and Assessment of Anti-HLA Antibodies}

We identified HLA class I (A, B) and II (DR) IgG using the FACSCanto II flow cytometer and a commercially available kit (FlowPRA Single Antigen Beads, One Lambda) according to the manufacturer's instructions. The DSA mean fluorescence intensity (MFI) values as the assumed MFI of the serum samples were compared with the negative control serum values for class I and class II beads. In accordance with Otten et al [8], MFI > 500 was defined as positive.

\section{Detection of C1q-binding DSAs}

The $\mathrm{C} 1 \mathrm{q}$ assay was performed by flow cytometry. Briefly, heatinactivated serum $\left(56^{\circ} \mathrm{C}, 30 \mathrm{~min}\right)$ was centrifuged at $16,000 \mathrm{rpm}$ for $10 \mathrm{~min}$, and $5 \mu \mathrm{L}$ of serum was mixed with $5 \mu \mathrm{L}$ of human $\mathrm{C} 1 \mathrm{q}$ HEPES buffer (One Lambda). FlowPRA Single Antigen Beads were added to the mixture and incubated for $20 \mathrm{~min}$ at room temperature. After the addition of FITC-conjugated anti-human C1q (Abcam, Cambridge, UK) and incubation for $20 \mathrm{~min}$ at room temperature, the beads were washed twice and the samples were analyzed using the FACSCanto II flow cytometer. In accordance with Thammanichanond et al (2014), Thammanichanond et al (2016), and Crespo et al $[15,18,19]$, MFI $>500$ was defined as positive.

\section{Immunosuppression Protocol}

With regard to KT, CDC-XM T-cell-positive patients were excluded. Patients who underwent KT were administered $20 \mathrm{mg}$ of basiliximab on the day of surgery and postoperative day 4 . The orally administered immunosuppressive agents were tacrolimus, mycophenolate mofetil, and methylprednisolone. ABO-compatible KT recipients started these immunosuppressive agents on preoperative day 7. ABO-incompatible or FCXM T-cell-positive KT recipients received an oral immunosuppressant from preoperative day 14 and rituximab $200 \mathrm{mg} /$ body on preoperative day 7, and underwent 1 to 5 plasmapheresis treatments depending on their $\mathrm{ABO}$ antibody titer or DSA MFI value before transplantation.

\section{Definition of Delayed Graft Function}

After KT, not only rejection and graft loss, but also delayed graft function (DGF) was reported to be associated with preformed DSAs [20]. Therefore, we examined DGF as an outcome parameter. DGF was indicated when 1 of the following criteria was fulfilled [21]: 1 . serum creatinine $>500 \mu \mathrm{mol} / \mathrm{L}$ throughout the first postoperative week; 2 . more than 1 dialysis session required during the first postoperative week; or 3. occurrence of oliguria ( $<1 \mathrm{~L} /$ day) within 2 days after transplantation. We adopted these criteria because clearly elevated serum creatinine and oliguria were regarded as clinical indications for poor graft function and were taken into account in a 
previously reported definition of DGF [21]. Furthermore, Peräsaari et al [20] described that a need for dialysis after transplantation may not always indicate DGF and may originate from pre-KT dialysis practices and fluid status or poor potassium balance after transplantation. Importantly, decisions on the need for dialysis are based on physicians' individual interpretations of the postoperative clinical status.

\section{Allograft Biopsy Policy and Pathological Interpretation}

We performed a protocol biopsy (PB) at 3 and 12 months posttransplantation. All biopsy specimens were scored according to the Banff 2013 classification [22]. Patients with acute rejection were classified into borderline changes, acute T-cell-mediated rejection (TMR; Banff grade IA or higher), and/or acute AMR. Subclinical acute rejection was defined as rejection diagnosed by $\mathrm{PB}$ without an increase of $>15 \%$ in the serum creatinine concentration from baseline (defined as mean serum creatinine concentration at 3 months before $\mathrm{PB}$ ) and no previous rejection episodes within 1 month [23]. If patients showed an unexplained increase in the serum creatinine concentration, including DGF lasting for more than 7 days, we performed an "indication biopsy" using the same procedure. All biopsy specimens were evaluated by 2 experienced pathologists (A.T. and K.M.) who reached a consensus using a dual light microscope. Both pathologists were blinded to the results of the C1q assay.

\section{Treatment for Acute Rejection}

When a patient was diagnosed as having acute rejection, treatment based on the following strategies was conducted. For acute TMR, steroid-pulse therapy was performed for 3 days depending on the grade of rejection and the patient's condition, such as infection or previous disease. For steroid-resistant rejection, patients were treated with anti-thymocyte globulin. Patients diagnosed with acute AMR were treated by plasmapheresis and intravenous immunoglobulin. Some patients also received rituximab.

\section{Graft and Patient Outcomes}

We investigated graft loss and patient death throughout the observation period. Graft loss was defined as return to dialysis, graft removal, or retransplantation.

\section{Statistical Analysis}

The normality of distribution for continuous variables was tested by the Shapiro-Wilks test. Data are presented as mean \pm SD for normally distributed variables, median (range) for non-normally distributed variables, and number $(\%)$ for categorical data. All statistical analyses were performed with JMP13 for Windows (SAS Institute, Cary, NC, United States). The Wilcoxon test was used to assess differences in continuous and ordinal variables between the 2 groups. The chi-square test and Fisher's exact probability test were used for categorical data. A Kaplan-Meier curve followed by the log-rank test was used to assess graft survival and cumulative incidence of acute AMR/TMR in the 2 groups. Univariate and multivariate logistic regression analyses were performed to determine the factors associated with DGF and CDC-XM T-cell-positivity. $P<.05$ was defined as significant for all statistical analyses.

\section{RESULTS}

The baseline characteristics and immunological data are shown in Table 1. All 44 patients with preformed IgG DSAs were tested with the $\mathrm{C} 1 \mathrm{q}$ assay. There were 17 patients with C1q-binding DSAs and 27 patients without C1q-binding DSAs. There were no significant differences between the 2 groups for recipient age, recipient sex, donor type, donor age, panel-reactive antibody-positivity, number of DSAs, HLA mismatch, retransplantation, and previous pregnancy. CDC-XM T-cell-positivity $(P=.0012)$, FCXM T-cell-positivity $(P=.0333)$, and previous blood transfusion $(P=$ .0174) were significantly higher in patients with C1q-binding DSAs than in patients without C1q-binding DSAs. DSA MFI values were significantly higher in patients with C1qbinding DSAs than in patients without C1q-binding DSAs $(P=.0009)$. Of the 44 patients, 36 patients underwent KT. The baseline characteristics of these 36 patients with and without C1q-binding DSAs are shown in Table 2. DSA MFI values $(P=.0292)$ and previous blood transfusion $(P=$ $.0049)$ were significantly greater in patients with C1qbinding DSAs than in patients without C1q-binding DSAs.

Table 1. Baseline Clinical Characteristics of All 44 Patients

\begin{tabular}{|c|c|c|c|}
\hline Parameters & With C1q-Binding DSAs $(n=17)$ & Without C1q-Binding DSAs $(\mathrm{n}=27)$ & $P$ Value \\
\hline Recipient age (years), median (range) & $52(4-64)$ & $51(11-73)$ & .6554 \\
\hline Recipient sex, female/male & $12 / 5$ & $21 / 6$ & .5939 \\
\hline Donor age (years), median (range) & $57(25-65)$ & $55(24-75)$ & .2830 \\
\hline Deceased donor, n (\%) & $1(5.8 \%)$ & $3(11.2)$ & .5459 \\
\hline \multicolumn{4}{|l|}{ Immunology } \\
\hline CDC-XM T-cell-positive, n (\%) & $5(29.4)$ & $0(0)$ & .0012 \\
\hline FCXM T-cell-positive, n (\%) & $13(76.4)$ & $12(44.4)$ & .0333 \\
\hline PRA screening class 1 -positive, $n$ (\%) & $14(82.4)$ & $20(74.0)$ & .5183 \\
\hline PRA screening class 2-positive, $\mathrm{n}(\%)$ & $11(64.8)$ & $17(63.0)$ & .9068 \\
\hline DSA MFI value, median (range) & $10,974(793-43,706)$ & $2764(23,174-376)$ & .0009 \\
\hline Number of DSAs, median (range) & $2(1-3)$ & $1(1-3)$ & .2514 \\
\hline HLA mismatch, median (range) & $3(2-5)$ & $4(2-6)$ & .4375 \\
\hline \multicolumn{4}{|l|}{ Presensitization events } \\
\hline Retransplantation, n (\%) & $5(29.4)$ & $2(7.4)$ & .0543 \\
\hline Previous blood transfusion, $\mathrm{n}(\%)$ & $9(53.0)$ & $5(18.6)$ & .0174 \\
\hline Previous pregnancy, $\mathrm{n}(\%)$ & $11(64.8)$ & $19(70.4)$ & .6954 \\
\hline
\end{tabular}

Abbreviations: CDC-XM, complement-dependent cytotoxicity crossmatch; DSAs, donor-specific anti-human leukocyte antigen antibodies; FCXM, flow cytometry crossmatch; HLA, human leukocyte antigen; MFI, mean fluorescence intensity; PRA, panel-reactive antibody. 
Table 2. Clinical Characteristics of the 36 Patients Who Underwent Kidney Transplantation

\begin{tabular}{|c|c|c|c|}
\hline Parameters & With C1q-Binding DSAs $(n=11)$ & Without C1q-Binding DSAs $(n=25)$ & $P$ Value \\
\hline Recipient age (years), median (range) & $41(4-61)$ & $53(16-73)$ & .1692 \\
\hline Recipient sex, female/male & $8 / 3$ & $20 / 5$ & .6332 \\
\hline Donor age (years), median (range) & $52(25-64)$ & $54(24-75)$ & .1261 \\
\hline Deceased donor, n (\%) & $1(9.0)$ & $2(8.0)$ & .9138 \\
\hline \multicolumn{4}{|l|}{ Immunology } \\
\hline CDC-XM T-cell-positive, n (\%) & $0(0)$ & $0(0)$ & - \\
\hline FCXM T-cell-positive, n (\%) & 7 (63.6) & $12(48.0)$ & .3841 \\
\hline PRA screening class 1-positive, $n$ (\%) & $8(72.8)$ & $18(72.0)$ & .9642 \\
\hline PRA screening class 2-positive, n (\%) & 7 (63.6) & $16(64.0)$ & .9833 \\
\hline DSA MFI value, median (range) & $7442(793-43,706)$ & $2803(376-23,174)$ & .0292 \\
\hline Number of DSAs, median (range) & $1(1-3)$ & $1(1-2)$ & .6225 \\
\hline ABO-incompatible KT, n (\%) & $5(45.4)$ & $6(24.0)$ & .2054 \\
\hline HLA mismatch, median (range) & $3(2-5)$ & $4(2-6)$ & .4339 \\
\hline \multicolumn{4}{|l|}{ Presensitization events } \\
\hline Retransplantation, $\mathrm{n}(\%)$ & $3(27.3)$ & $1(4.0)$ & .0504 \\
\hline Previous blood transfusion, $\mathrm{n}(\%)$ & $7(63.6)$ & $4(16.0)$ & .0049 \\
\hline Previous pregnancy, n (\%) & $7(63.6)$ & $18(72.0)$ & .6158 \\
\hline \multicolumn{4}{|l|}{ Desensitization } \\
\hline Rituximab administration, n (\%) & $10(90.9)$ & $19(76.0)$ & .2710 \\
\hline Number of plasmapheresis sessions, median (range) & $3(3-3)$ & $3(1-4)$ & .3482 \\
\hline
\end{tabular}

Abbreviations: CDC-XM, complement-dependent cytotoxicity crossmatch; DSAs, donor-specific anti-human leukocyte antigen antibodies; FCXM, flow cytometry crossmatch; HLA, human leukocyte antigen; KT, kidney transplantation; MFI, mean fluorescence intensity; PRA, panel-reactive antibody.

The clinical outcomes of the $36 \mathrm{KT}$ recipients with and without C1q-binding DSAs are shown in Table 3. Incidence of DGF was significantly higher in patients with C1q-binding DSAs than in patients without C1q-binding DSAs $(P=$ .0419). There were no significant differences between the 2 groups for glomerular filtration rate, urine protein/creatinine ratio, biopsy-proven acute TMR or AMR, patient death, and graft loss. There were no significant differences between the 2 groups in the death-censored graft survival rates (Fig 1A). The cumulative incidence of biopsy-proven acute rejection (BPAR) diagnosed by both protocol and indication biopsies was $33.5 \%$ in patients without C1qbinding DSAs and $32.5 \%$ in patients with C1q-binding DSAs, with no significant difference (Fig 1B). Among the patients with BPAR, $4(50 \%)$ patients without C1q-binding DSAs and $2(40 \%)$ patients with C1q-binding DSAs were diagnosed as acute AMR (Fig 2). Univariate and multivariate logistic regression analyses were performed to investigate the factors associated with DGF (Table 4), and CDCXM T-cell positivity (Table 5). DSA MFI value was significantly associated with DGF $(P=.0124)$, while C1qbinding DSAs had no association with DGF.

\section{DISCUSSION}

In this study, we demonstrated that preformed C1q-binding DSAs were highly correlated with DSA MFI values and CDC-XM-positivity. However, preformed C1q-binding DSAs were not associated with outcomes after KT in patients with CDC-XM-negativity.

Although not examined in the present study, it is known that IgG subclasses have different C1q-binding affinities, with most potent binding for IgG3 followed by IgG1, which is predominant, very weak binding for IgG2, and no binding for IgG4 [24]. However, the underlying cause of immunization (pregnancy, blood cell transfusion, grafting) was reported to have a low impact on the subclass repartition $[25,26]$. Therefore, it is supposed that the amounts of IgG, represented by the MFI, mainly influence the interaction with C1q. Although we showed that previous transfusion was associated with C1q-binding

Table 3. Outcomes After Kidney Transplantation

\begin{tabular}{|c|c|c|c|}
\hline Parameters & With C1q-Binding DSAs $(n=11)$ & Without C1q-Binding DSAs $(n=25)$ & $P$ Value \\
\hline Delayed graft function, $\mathrm{n}(\%)$ & $6(54.6)$ & $5(20.0)$ & .0419 \\
\hline GFR at 3 months $\left(\mathrm{mL} / \mathrm{min} / 1.73 \mathrm{~m}^{2}\right)$, mean $\pm \mathrm{SD}$ & $62.2 \pm 20.0$ & $55.0 \pm 14.8$ & .2801 \\
\hline GFR at 12 months $\left(\mathrm{mL} / \mathrm{min} / 1.73 \mathrm{~m}^{2}\right)$, mean $\pm \mathrm{SD}$ & $56.2 \pm 21.6$ & $50.8 \pm 14.2$ & .4882 \\
\hline Proteinuria at 3 months (UPCR; $\mathrm{g} / \mathrm{gcr}$ ), median (range) & $0.17(0.08-1.67)$ & $0.13(0.05-0.61)$ & .7896 \\
\hline Proteinuria at 12 months (UPCR; g/gcr), median (range) & $0.12(0.06-3.58)$ & $0.16(0.03-2.73)$ & .4668 \\
\hline Acute T-cell-mediated rejection, $\mathrm{n}(\%)$ & $3(27.2)$ & $4(16.0)$ & .4413 \\
\hline Acute antibody-mediated rejection, $\mathrm{n}(\%)$ & $2(18.2)$ & $4(16.0)$ & .8723 \\
\hline Follow-up (days), mean $\pm S D$ & $864 \pm 472$ & $802 \pm 685$ & .7890 \\
\hline Patient death, $\mathrm{n}(\%)$ & $1(9.0)$ & $0(0)$ & .1185 \\
\hline Graft loss, n (\%) & $2(18.2)$ & $2(8.0)$ & .3876 \\
\hline
\end{tabular}

Abbreviations: DSAs, donor-specific anti-human leukocyte antigen antibodies; GFR, glomerular filtration rate; UPCR, urine protein/creatinine ratio. 

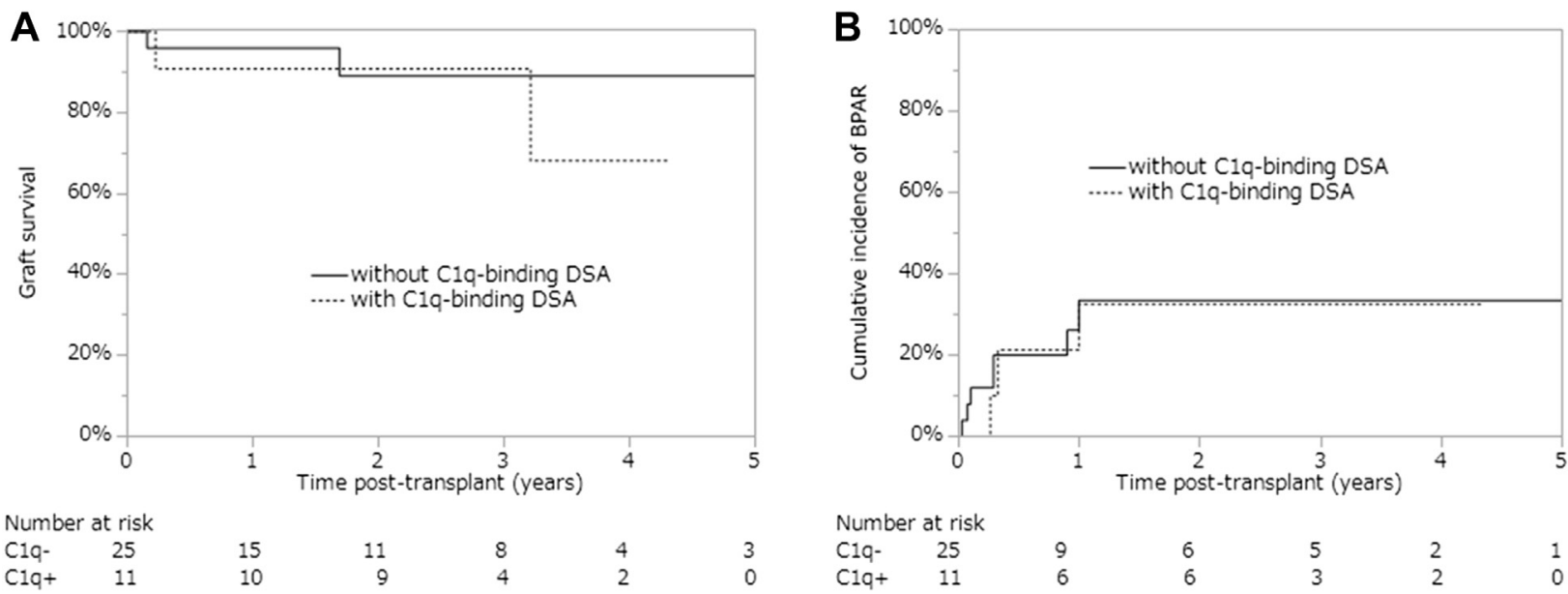

Fig 1. (A) Death-censored cumulative graft survival rates after KT in patients classified by the presence or absence of C1q-binding DSAs. The graft survival rates did not differ significantly between the 2 groups $(P=.5092)$. (B) The cumulative incidence of BPAR diagnosed by both protocol and indication biopsies was $33.5 \%$ in patients without C1q-binding DSAs and $32.5 \%$ in those with C1q-binding DSAs, with no significant difference $(P=.8354)$.

ability, previous transfusion was also associated with high DSA MFI. Therefore, preformed C1q-binding DSAs appeared to be correlated with both DSA MFI and previous transfusion.

The CDC-XM assay only detects complement-binding DSAs, while the SAB assay is designed to detect both complement-binding and non-complement-binding antibodies. As CDC-XM-positive crossmatches are strongly associated with hyperacute or acute AMR [4], preformed C1q-binding DSAs detected by the $\mathrm{C} 1 \mathrm{q}$ assay are considered to be strongly associated with AMR. In the present study, we
A Subclinical acute rejection

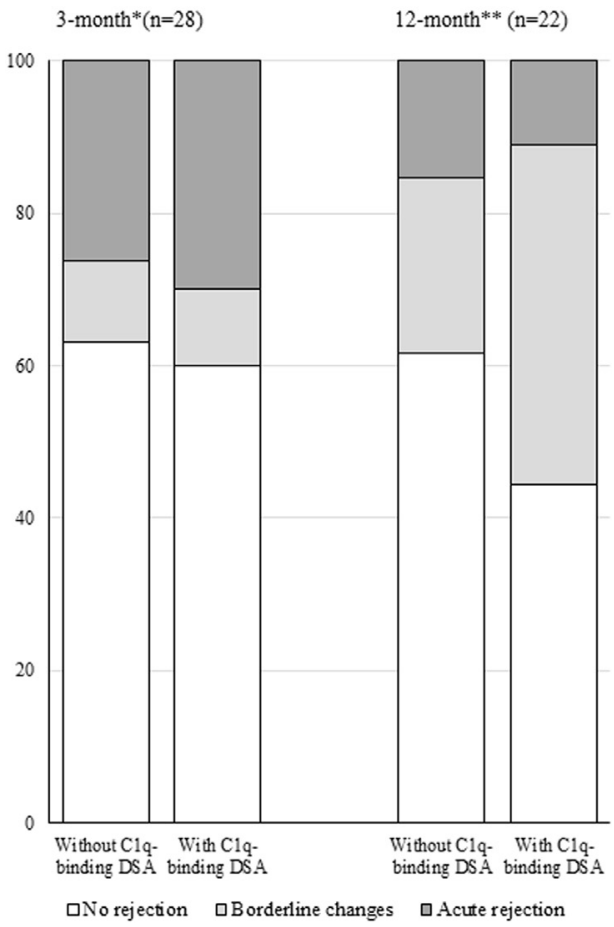

B

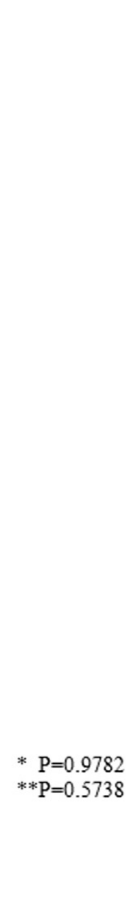

IF/TA grades

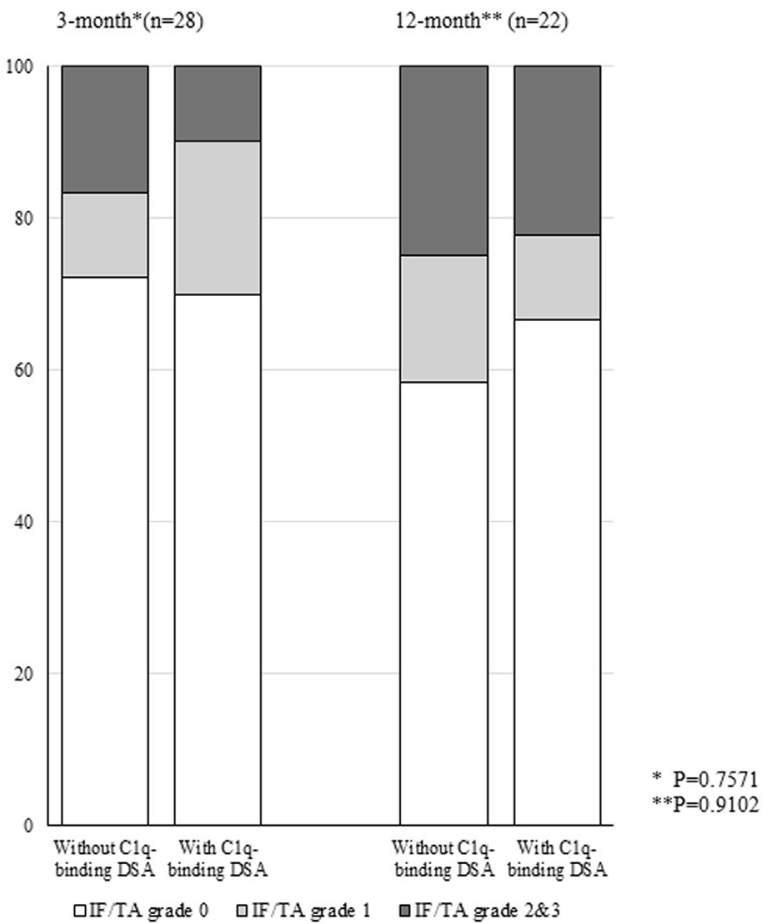

Fig 2. Rates of (A) acute rejection and (B) interstitial fibrosis/tubular atrophy (IF/TA) in the 3-month and 12-month protocol biopsies. The incidence of borderline changes/acute rejection (Banff grade la or higher) and degree of IF/TA did not differ significantly between the 2 groups in the 3-month and 12-month protocol biopsies. 
Table 4. Univariate and Multivariate Regression Analyses for Factors Associated With Delayed Graft Function

\begin{tabular}{|c|c|c|c|c|c|c|}
\hline \multirow[b]{2}{*}{ Parameter } & \multicolumn{3}{|c|}{ Univariate Analysis } & \multicolumn{3}{|c|}{ Multivariate Analysis } \\
\hline & OR & $95 \% \mathrm{Cl}$ & $P$ Value & OR & $95 \% \mathrm{Cl}$ & $P$ Value \\
\hline Recipient age & 1.03 & $0.98-1.10$ & .2195 & & ND & \\
\hline Recipient sex (female) & 3.88 & $0.42-36.29$ & .1810 & & ND & \\
\hline Donor age & 1.01 & $0.96-1.07$ & .6764 & & ND & \\
\hline Deceased donor & 1.15 & $0.09-14.19$ & .9138 & & ND & \\
\hline \multicolumn{7}{|l|}{ Immunology } \\
\hline FCXM T-cell-positive & 3.39 & $0.78-18.43$ & .1063 & & ND & \\
\hline PRA screening class 1-positive & 2.12 & $0.37-12.16$ & .4000 & & ND & \\
\hline PRA screening class 2-positive & 9.23 & $1.02-83.33$ & .0477 & 6.83 & $0.46-100.35$ & .1614 \\
\hline DSA MFI value (per 100) & 1.02 & $1.01-1.04$ & .0002 & 1.02 & $1.00-1.04$ & .0124 \\
\hline Number of DSAs & 2.24 & $0.99-5.08$ & .0542 & & ND & \\
\hline C1q-binding DSAs & 4.80 & $1.03-22.37$ & .0458 & 2.44 & $0.42-29.98$ & .2377 \\
\hline ABO-incompatible $\mathrm{KT}$ & 1.46 & $0.31-6.63$ & .6188 & & ND & \\
\hline HLA mismatch & 1.40 & $0.82-2.50$ & .2221 & & ND & \\
\hline \multicolumn{7}{|l|}{ Presensitization events } \\
\hline Retransplantation & 2.56 & $0.27-24.10$ & .3876 & & ND & \\
\hline Previous blood transfusion & 2.64 & $0.58-12.28$ & .2054 & & ND & \\
\hline Previous pregnancy & 6.67 & $0.73-60.52$ & .0919 & & ND & \\
\hline \multicolumn{7}{|l|}{ Desensitization } \\
\hline Rituximab administration & - & - & .0158 & - & - & .1381 \\
\hline Number of plasmapheresis sessions & 1.03 & $0.73-1.41$ & 08671 & & ND & \\
\hline
\end{tabular}

Abbreviations: $\mathrm{Cl}$, confidence interval; DSAs, donor-specific anti-human leukocyte antigen antibodies; FCXM, flow cytometry crossmatch; HLA, human leukocyte antigen; KT, kidney transplantation; MFI, mean fluorescence intensity; ND, not done; OR, odds ratio; PRA, panel-reactive antibody.

also found that preformed C1q-binding DSAs were clearly associated with CDC-XM T-cell-positivity. However, we were unable to show a significant effect of C1q-binding DSAs on KT outcomes, in accordance with a previous report [18]. Several reasons can be considered for this finding. First, the presence of $\mathrm{C1q}$ does not predict whether the complement cascade will proceed, or simply result in $\mathrm{C} 4$ deposition on the cell surface. The downstream production of $\mathrm{C} 3 \mathrm{~d}$ may predict complete complement activation more accurately [27]. Second, we speculate that exclusion of CDC-XM T-cell-positive donors may lead to the selection of lower-strength complement-binding DSAs, which will have an impact on the overall clinical results. This notion is supported by Chin et al [14], who reported that AMR developed within 1 month post- transplantation in pediatric heart transplantation patients with preformed C1q-binding DSAs including CDC-XMpositive patients. They suggested that $\mathrm{C} 1 \mathrm{q}$ testing in pretransplant sera of patients on the waiting list for heart transplantation would be useful and could be a substitute for CDC-XM testing with high reliability.

In the present study, we found that DSA MFI values had a stronger association with DGF than C1q-binding ability. Peräsaari et al [20] implied that pre-existing DSAs, even with CDC-XM-negativity, pose a significant risk for DGF. It has been hypothesized, but not confirmed, that a potential immunological mechanism involving antigen-antibody reactions can cause an AMR episode that is interpreted as DGF [28]. Therefore, our findings suggest that the amount of $\mathrm{IgG}$,

Table 5. Univariate and Multivariate Regression Analyses for Factors Associated With CDC-XM T-cell Positivity

\begin{tabular}{|c|c|c|c|c|c|c|}
\hline \multirow[b]{2}{*}{ Parameter } & \multicolumn{3}{|c|}{ Univariate Analysis } & \multicolumn{3}{|c|}{ Multivariate Analysis } \\
\hline & OR & $95 \% \mathrm{Cl}$ & $P$ Value & OR & $95 \% \mathrm{Cl}$ & $P$ Value \\
\hline Recipient age & 1.08 & $0.99-1.21$ & .0769 & 1.16 & $1.02-1.50$ & .0142 \\
\hline Recipient sex (female) & 1.38 & $0.18-28.68$ & .7793 & & ND & \\
\hline Donor age & 1.00 & $0.93-1.03$ & .9699 & & ND & \\
\hline \multicolumn{7}{|l|}{ Immunology } \\
\hline DSA MFI (per 100) & 12.87 & $0.48-347.78$ & .1196 & 1.00 & $0.98-1.01$ & .8401 \\
\hline Number of DSAs & 1.57 & $0.57-4.34$ & .2037 & & ND & \\
\hline C1q-binding DSAs & - & - & .0012 & - & - & .0007 \\
\hline ABO-incompatible KT & 1.50 & $0.18-10.22$ & .6817 & & ND & \\
\hline HLA mismatch & 1.08 & $0.46-2.15$ & .9584 & & ND & \\
\hline \multicolumn{7}{|l|}{ Presensitization events } \\
\hline Retransplantation & 1.38 & $0.06-11.57$ & .7961 & & ND & \\
\hline Previous blood transfusion & 1.50 & $0.18-10.22$ & .6817 & & ND & \\
\hline Previous pregnancy & 2.00 & $0.36-41.24$ & .5317 & & ND & \\
\hline
\end{tabular}

Abbreviations: CDC-XM, complement-dependent cytotoxicity crossmatch; CI, confidence interval; DSAs, donor-specific anti-human leukocyte antigen antibodies; HLA, human leukocyte antigen; KT, kidney transplantation; MFI, mean fluorescence intensity; ND, not done; OR, odds ratio. 
represented by the MFI value, is a more potent factor for immunological reactions in grafts than C1q-binding ability.

\section{CONCLUSIONS}

There are several limitations to the present study. First, the study had a small sample size, was a retrospective cohort study, had a short meaningful follow-up time, included fewer male recipients, and was not designed to investigate the amount of C1q-binding DSAs. Second, although the flow cytometric $\mathrm{C} 1 \mathrm{q}$ assay can detect anti-Cw or anti-DQ DSAs, similar to the Luminex assay, we did not examine DSAs against certain loci such as DQ that were reported to increase the incidence of de novo complement-binding antibodies [6]. Third, the desensitization protocol, including the number of plasmapheresis treatments, was not precisely regulated.

The present study suggests that preformed C1q-binding DSAs are highly correlated with DSA MFI values and CDC-XM-positivity. For patients with CDC-XM-negativity, preformed C1q-binding DSAs are not associated with outcomes after KT. Further research with a larger sample size is necessary to establish the clinical significance of preformed C1q-binding DSAs.

\section{ACKNOWLEDGMENTS}

The authors wish to thank Alison Sherwin, $\mathrm{PhD}$, from Edanz Group (www.edanzediting.com/ac) for editing a draft of this manuscript.

\section{REFERENCES}

[1] Pascual J, Zamora J, Pirsch JD. A systematic review of kidney transplantation from expanded criteria donors. Am J Kidney Dis 2008;52:553-86.

[2] Montgomery RA, Zachary AA. Transplanting patients with a positive donor-specific crossmatch: a single center's perspective. Pediatr Transplant 2004;8:535-42.

[3] Burns JM, Cornell LD, Perry DK, et al. Alloantibody levels and acute humoral rejection early after positive crossmatch kidney transplantation. Am J Transplant 2008;8:2684-94.

[4] Vo AA, Lukovsky M, Toyoda M, et al. Rituximab and intravenous immune globulin for desensitization during renal transplantation. N Engl J Med 2008;359:242-51.

[5] Patel R, Terasaki PI. Significance of the positive crossmatch test in kidney transplantation. New Engl J Med 1969;280:735-9.

[6] Lefaucheur C, Loupy A, Hill GS, et al. Preexisting donorspecific HLA antibodies predict outcome in kidney transplantation. J Am Soc Nephrol 2010;21:1398-406.

[7] Singh N, Djamali A, Lorentzen D, et al. Pretransplant donorspecific antibodies detected by single-antigen bead flow cytometry are associated with inferior kidney transplant outcomes. Transplantation 2010;90:1079-84.

[8] Otten HG, Verhaar MC, Borst HPE, Hené RJ, van Zuilen AD. Pretransplant donor-specific HLA class-I and -II antibodies are associated with an increased risk for kidney graft failure. Am J Transplant 2012;12:1618-23.

[9] Aubert V, Venetz JP, Pantaleo G, Pascual M. Low levels of human leukocyte antigen donor-specific antibodies detected by solid phase assay before transplantation are frequently clinically irrelevant. Hum Immunol 2009;70:580-3.

[10] Süsal C, Ovens J, Mahmoud K, et al. No association of kidney graft loss with human leukocyte antigen antibodies detected exclusively by sensitive Luminex single-antigen testing: a Collaborative Transplant Study report. Transplantation 2011;91:883-7.

[11] Feucht HE, Felber E, Gokel MJ, et al. Vascular deposition of complement-split products in kidney allografts with cellmediated rejection. Clin Exp Immunol 1991;86:464-70.

[12] Collins AB, Schneeberger EE, Pascual MA, et al. Complement activation in acute humoral renal allograft rejection: diagnostic significance of $\mathrm{C} 4 \mathrm{~d}$ deposits in peritubular capillaries. J Am Soc Nephrol 1999;10:2208-14.

[13] Böhmig GA, Exner M, Habicht A, et al. Capillary C4d deposition in kidney allografts: a specific marker of alloantibodydependent graft injury. J Am Soc Nephrol 2002;13:1091-9.

[14] Chin C, Chen GE, Sequeria F, et al. Clinical usefulness of a novel $\mathrm{C} 1 \mathrm{q}$ assay to detect immunoglobulin $\mathrm{G}$ antibodies capable of fixing complement in sensitized pediatric heart transplant patients. J Heart Lung Transplant 2011;30:158-63.

[15] Thammanichanond D, Mongkolsuk T, Rattanasiri S, et al. Significance of Clq-fixing donor-specific antibodies after kidney transplantation. Transplant Proc 2014;46:368-71.

[16] Yabu JM, Higgins JP, Chen G, Sequeira F, Busque S, Tyan DB. Clq-fixing human leukocyte antigen antibodies are specific for predicting transplant glomerulopathy and late graft failure after kidney transplantation. Transplantation 2011;91:342-7.

[17] Loupy A, Lefaucheur C, Vernerey D, et al. Complementbinding anti-HLA antibodies and kidney-allograft survival. New Engl J Med 2013;369:1215-26.

[18] Thammanichanond D, Wiwattanathum P, Mongkolsuk T, et al. Role of pretransplant complement-fixing donor-specific antibodies identified by $\mathrm{Clq}$ assay in kidney transplantation. Transplant Proc 2016;48:756-60.

[19] Crespo M, Torio A, Mas V, et al. Clinical relevance of pretransplant anti-HLA donor-specific antibodies: does C1qfixation matter? Transpl Immunol 2013;29:28-33.

[20] Peräsaari JP, Kyllönen LE, Salmela KT, Merenmies JM. Pre-transplant donor-specific anti-human leukocyte antigen antibodies are associated with high risk of delayed graft function after renal transplantation. Nephrol Dial Transplant 2016;31: 672-8.

[21] Halloran PF, Aprile MA, Farewell V, et al. Early function as the principal correlate of graft survival. A multivariate analysis of 200 cadaveric renal transplants treated with a protocol incorporating antilymphocyte globulin and cyclosporine. Transplantation 1988;46:223-8.

[22] Haas M, Sis B, Racusen LC, et al. Banff 2013 meeting report: inclusion of $\mathrm{C} 4 \mathrm{~d}$-negative antibody-mediated rejection and antibody-associated arterial lesions. Am J Transplant 2014;14: 272-83.

[23] Djamali A, Kaufman DB, Ellis TM, Zhong W, Matas S, Samaniego M. Diagnosis and management of antibody-mediated rejection: current status and novel approaches. Am J Transplant 2014; $14: 255-71$.

[24] Tao MH, Smith RI, Morrison SL. Structural features of human immunoglobulin $\mathrm{G}$ that determine isotype-specific differences in complement activation. J Exp Med 1993;178:661-7.

[25] Lowe D, Higgins R, Zehnder D, Briggs DC. Significant IgG subclass heterogeneity in HLA-specific antibodies: implications for pathogenicity, prognosis, and the rejection response. Hum Immunol 2013;74:666-72.

[26] Prigent A, Maillard N, Absi L, et al. From donor to recipient: current questions relating to humoral alloimmunization. Antibodies 2014;3:130-52.

[27] Comoli P, Cioni M, Tagliamacco A, et al. Acquisition of C3d-binding activity by de novo donor-specific HLA antibodies correlates with graft loss in nonsensitized pediatric kidney recipients. Am J Transplant 2016;16:2106-16.

[28] Peeters P, Terryn W, Vanholder R, Lameire N. Delayed graft function in renal transplantation. Curr Opin Crit Care 2004;10:489-98. 